SlavVaria 1/2021. 203-214

DOI: $10.15170 /$ SV.1/2021.203

\author{
ЖУЖАННА ДИМЕШИ \\ (Будапешт, Венгрия)
}

\title{
Живописные реминисценции в фильме Владимира Мотыля «Белое солнце пустыни» ${ }^{1}$
}

Аннотация: Советский игровой фильм «Белое солнце пустыни» режиссера В. Мотыля (1970) считается вещью эпохальной во многих отношениях. Значительны и обстоятельства съёмки, показа, выхода в прокат, зрительской реакции, и жанр, и формальный язык самого фильма. В статье речь пойдёт о съёмочном процессе в студии ЭТО, жанровом своеобразии истерна и некоторых особенностях его формального языка, а именно о реминисценциях картин художников Коровина, Кузнецова, Кустодиева, Ларионова, Малевича, Саряна, Якулова.

Ключевые слова: Владимир Мотыль, «Белое солнце пустыни», истерн, живопись начала 20 века

Режиссёр Владимир Мотыль (1927-2010) - фигура в советском интеллектуальном пейзаже своеобразная. Ни к открытым инакомыслящим, ни к молчаливым разномыслящим он не принадлежал, а располагался где-то посредине. Родители, бабушка и дедушка, и сам он в детстве были прямыми жертвами сталинских репрессий, но яркая индивидуальность, свободный дух поднимали его и над личными, и над историческими трагедиями. Он жил жизнью независимого индивидуума, соотносясь с независящими от времени и места человеческими мерками. «Я всегда чувствовал себя свободным» - произнёс он в 2008 году (ТАЙНЫ КИНО 2019: URL), что несколько ошарашивает из уст человека, чье детство прошло в ссылке, бабушка и дед погибли во время войны в белорусском гетто, кому снимать позволяли раз лет в пять, чьи фильмы пускали в прокат неохотно и скупо, а то и вовсе запрещали. Мотыль был человеком жизнелюбивым, обаятельным, добрым, и пафос, отчаянье, брюзжанье, обида, злоба как средства самозащиты от ударов судьбы и несправедливости были бы ниже его достоинства. Он был верен себе, не прогибался под идеологическим нажимом, но и не считал себя жертвой обсто-

1 Доклад прозвучал 14 мая 2021 г. на Кафедре русского языка и литературы Будапештского университета им. Лоранда Этвеша в рамках XI завершающей учебный год конференции, посвящённой памяти Анны Хан. Связь с духовным наследием учителя автор стремится выразить, выбрав тему из области интермедиальности. 
ятельств, а всякий раз шаг за шагом, медленно, но неотступно шёл к цели - в соответствии с собственными принципами. Пребывая как бы и вне системы, и внутри неё, вроде сказочного Иванушки-дурачка, который хорошо знает: чтобы достичь цели, нужно преодолеть множество препятствий. Главный герой «Белого солнца пустыни», самого успешного фильма Мотыля, солдат Сухов - из той же породы.

Коллеги вспоминают о Мотыле (ТРОИЦКИЙ 2007: URL; HACOHОВ 2012: URL), как о фантастически щедро одарённом режиссёре, которому так и не довелось полностью раскрыться из-за неудачи. (Неизменный мотив в профессиональных оценках: мол, творческое наследие в десять игровых фильмов - маловато). По-моему, говорить об удаче тут не самый адекватный подход, тем более, что Мотыль, оглядываясь на свою творческую биографию, сам замечал, сколько раз именно удача помогало ему выпутаться из очередной политической ловушки ${ }^{2}$. Речь ведь идет о художнике, каждая вещь которого существует вне системы координат социалистического реализма, но при этом не противопоставлена ей, а как бы парит надо всеми этими жёсткими идеологическими и художественными установлениями. «Фильм - это моя война» (ТРОИЦКИЙ 2007: URL), - говорил он, и тут всё сразу - и сраженья за саму возможность съемок и показа, и чисто творческий процесс, когда воюешь уже с самим собой, как всякий художник ${ }^{3}$.

Третий полнометражный фильм Владимира Мотыля «Белое солнце пустыни» вышел на советские экраны в 1970 году и собрал наибольшее число просмотров. 130 стран - и Венгрия в их числе - приобрели прокатные лицензии на него, но официального отклика по существу не последовало. Советское начальство по вопросам кинематографии и не запретило его, и говорить о нём не говорило. Слава между тем продолжала расти, он стал одним из любимейших фильмов советской эпохи, у космонавтов считался талисманом, а это в Советском Союзе было надёжной защитой, ведь начиная с шестидесятых самым выдающимся типом народного героя был космонавт, что не релятивизировалось ни при каком идеологическом поветрии.

«Белое солнце пустыни» считается вещью эпохальной во многих отношениях. И как факт творческой биографии режиссёра - тут и обстоятельства съёмки, показа, выхода в прокат, зрительской реакции, и

\footnotetext{
2 Так, прокат каждого из трёх самых знаменитых его фильмов - «Женя, Женечка и «катюша» (1967), «Белое солнце пустыни» (1970), «Звезда пленительного счастья» (1979) - осуществился лишь благодаря случайности: им - всякий раз нежданно - везло понравиться какому-нибудь высокопоставленному партийному чиновнику (ТАЙНЫ КИНО 2019: URL).

3 Родственными ему по духу мне представляются Андрей Платонов, Юрий Норштейн или Александр Сокуров. К духовному родству с Платоновым я ещё возвращусь в дальнейшем.
} 
не в последнюю очередь с позиции жанра, формального языка самого фильма. В дальнейшем речь пойдёт о съёмочном процессе, жанровом своеобразии фильма и некоторых особенностях его формального языка.

\section{Съёмка}

Два момента удачи подвели Мотыля к третьему его полнометражному фильму. Во второй половине шестидесятых советская кинематография задалась целью в условиях социалистического лагеря достичь жанрового разнообразия и кассового успеха, присущих американскому и европейскому кинопроизводству. Под знаком этих устремлений родился, например, «Ну погоди» - советский вариант «Тома и Джерри» или жанр истерна - восточноевропейской адаптации вестерна. Именно для реализации этих устремлений и была создана в 1964 году первая такая экспериментальная киностудия, целью и задачей которой были успех у публики и самоокупаемость. Находясь под контролем государства, она тем не менее самостоятельно хозяйствовала, была относительно свободна в планировании собственной деятельности, сама заключала договора, сама выбирала авторов. Это была студия ЭТО, возглавляли её Григорий Чухрай $^{4}$ и Владимир Познер ${ }^{5}$-старший. В 1968 году на ЭТО решено было снять приключенческий фильм в стиле вестерна о гражданской войне, главным образом для юношества. Сначала написать сценарий поручили Андрею Кончаловскому и Фридриху Горенштейну ${ }^{6}$, но работа не заладилась (оба были увлечены своим, и не особо заинтересовались). Чтобы сдвинуть дело с мёртвой точки, к работе привлекли двух других сценаристов - Валентина Ежова, соавтора сценария «Баллады о солдате» и Рустама Ибрагимбекова ${ }^{7}$. Результатом не были довольны ни заказчики, ни авторы. Так что Ежов отправился в Среднюю Азию в надежде собрать там какие-нибудь интересные истории от ветеранов Первой мировой и Гражданской войн. Там он услышал историю об одном басмаче, который

${ }^{4}$ Григорий Чухрай (1920-2001) - кинорежиссёр, преподаватель ВГИК-а, выдающаяся фигура оттепельных лет. Среди прочего снял шедшую с большим успехом и в Венгрии «Балладу о солдате» (1959).

${ }^{5}$ Владимир Александрович Познер (1908-1975) - кинематографист с интересной судьбой, работал в основном как продюсер, организатор кинопроизводства и проката с многолетним опытом работы на американских и французских киностудиях.

${ }^{6}$ Фридрих Наумович Горенштейн (1932-2002) - писатель, драматург. За ним числится множество сценариев к фильмам семидесятых, снискавших мировую славу, среди них «Солярис» Тарковского (1972) и «Раба любви» Михалкова (1975).

7 Рустам Ибрагимбеков (1939-) - сценарист, режиссёр, продюсер. С его именем связано более 60 фильмов, он многолетний соратник Никиты Михалкова, самые известные из их общих проектов - «Утомлённые солнцем» (1994) и «Сибирский цирюльник» (1998). 
якобы, спасаясь бегством не то в двадцать первом, не то в двадцать втором году, бросил в пустыне на произвол судьбы свой гарем. Байка оказалась вполне прочной опорой для всего замысла. А ещё ветераны рассказали Ежову об офицере таможенной службы Михаиле Дмитриевиче Поспелове, который больше двадцати лет (с 1913 по 1925 гг.) героически и верно преданно защищал один из участков русско-персидской границы, взимал причитающиеся пошлины и держал в узде нарушителей, контрабандистов и местные банды, независимо от того, в чьих руках была власть в округе. Знанием своего дела, богатырским сложеньем, смелостью и любовью к отечеству он прославился по всему восточному побережью Каспия. И послужил Ежову прообразом Павла Верещагина в картине.

Мотыль взялся за историю с тяжелым сердцем. «Белое солнце - это не моё, я подогнал под себя чужую одежду» ${ }^{8}$ - записал он в дневнике в 1968 году. Но урок престижного художника Михаила Ромма, с которым лично советовался начинающий режиссер несколько лет раньше, помог преодолеть сомнения. Он продолжал заниматься сценарием с Ибрагимбековым и Ежовым, привлёк к работе Марка Захарова ${ }^{9}$, оговорил с Чухраем право во время съемок обращаться со сценарием по своему усмотрению. Дело в том, что обычно съёмочной группе не полагалось отклоняться от одобренного кинематографическим начальством сценария.

Кредо художника, считал Мотыль, и в страшные времена держаться идеалов добра, человечности и говорить об этом вслух. «Ужасно не доставало в этом сценарии доброты, любви. Потому что я веровал в силу пушкинского завета чувства добрые пробуждать в жестокий век» - писал он (КАК СОЗДАВАЛСЯ 2001: URL). Так явилась ему счастливая идея: пускай главный герой регулярно пишет письма не предусмотренной в сценарии далёкой любимой молодой жене. Автором воображаемых писем стал Марк Захаров. Эти литературные вставки, не требовавшие изменений в сюжете, и сместили фокус истории к доброте и любви.

\section{Жанр}

Стоит сделать краткое отступление о жанрах вестерна и «истерна». В шестидесятые годы как в Соединённых штатах, так и в Европе необычайную популярность набирал вестерн с американскими корнями. Благодаря актуальному потеплению в холодной войне кинопроизводство соцлагеря тоже подключилось к общему тренду и даже лидировало по части новшеств: родилось понятие красного вестерна. Под ним понимались фильмы, действительно снятые в жанре вестерна - но с участием киностудий соцстран, их съемочных групп. Легендарным Виннету соцлагеря стал Гойко Митич, снявшийся во множестве гэдээровских и югославских

\footnotetext{
${ }^{8}$ Фрагмент дневниковой записи Мотыля 1968 года (НАСОНОВ 2012).

${ }^{9}$ Марк Анатольевич Захаров (1933-2019) - писатель, актёр, режиссёр, сценарист. В дальнейшем тесно сотрудничал с Мотылём.
} 
фильмов. Особенность красного вестерна заключалась в том, что он изготовлялся не по советским образцам, напротив, зародившись в ГДР и Чехословакии, плодотворно повлиял затем и на советское кинопроизводство. Параллельно появилась и восточная адаптация вестерна истерн. Вместо прерий действие в таких фильмах разворачивается в степи или азиатских пустынях, а вместо индейцев главный герой-одиночка защищает местное угнетённое население. Основной конфликт вестерна всегда заключается в столкновении двух систем, где на одной стороне невинные и добрые, на другой - злые и агрессивные. Главный герой посторонний; согласно универсальным представлениям о добре и зле, но на индивидуальной нравственной основе он помогает невинным и добрым, не встраиваясь при этом ни в одну из систем. Действие почти всегда разворачивается на лоне суровой, но прекрасной природы. Главный герой, как правило, немногословен: за него говорят его действия и поступки, так что музыке достаётся ключевая роль. Эта формула и легла в основу сценария «Белого солнца пустыни». Одинокий посторонний герой тут Сухов, солдат-красноармеец, держащий путь домой. Роль злодея досталась Абдулле, главарю разбойничающей в пустыне банды. У Сухова два помощника - местный Саид, борющийся с несправедливостью собственной системы (Абдулла убил его отца) и офицер таможни Верещагин, тоже оказавшийся жертвой своей системы (царская армия оставила его на таможне одного и забыла о нём, а он продолжает честно исполнять свой долг). Роль ожидающих спасения униженных и порабощённых выпала женщинам гарема, им нужно было открыть путь к достойной жизни в Стране советов. Занятна в этом уравнении роль отряда красноармейцев. На первый взгляд отряд тут антипод Абдуллы, и хочет защитить беззащитных. Красноармейцы исполнены самых добрых намерений, но трусоваты и неуклюжи, то есть непригодны к выполнению задачи. Сцена с ними эпизодична, пародийна (но без изобличительного намерения). Что до «подлежащих» спасенью жён гарема, то судя по их редким репликам, они вовсе не намерены становиться эмансипированными советскими женщинами, ведь с концом подчинённости зависимость никуда не денется, а, наоборот, лишь возрастёт из-за полнейшей неясности будущего. Дилеммы звучат в фильме добродушнонасмешливо, безо всякого идеологического нажима, но дух общественной критики присутствует. В конечном счёте фильм не о войне, а о герое, который верен себе, своему долгу и далёкой любимой. Сухов киновариант крестьянского сына из русской сказки, доброго молодца. А его помощник Верещагин - современное воплощение былинного богатыря, всадника-великана. Пустыня - место, где правила исторического времени не действуют. Ни выдыхающаяся белая парадигма, ни победная красная ничего не значат здесь, где царит вечность, внеисторическое время. В фильме его олицетворяют трое стариков, которые не шевелясь, с недвижными лицами, сидят на земле в позе лотоса и наблюдают, как люди 
приходят и уходят, сражаются, живут, умирают. Они одну лишь пустыню принимают всерьёз, где вечное время и вечное пространство перетекают одно в другое, растворяются одно в другом, и всякий попавший сюда ищет свое место, время, роль. Главный герой Сухов способен перемещаться во всех временных плоскостях сразу, находить общий язык со всеми и с каждым и жить по ясным, простым и добрым правилам. Когда он решает, что исполнил уже свой долг (вверил спасённый гарем заботам красноармейцев), то покидает плоскость исторического времени и исчезает в пустыне. Вот что вышло из жанра вестерна в восточном его прочтении.

\section{Форма}

Самая бросающаяся в глаза особенность фильма - его лаконичность и простота. Это равно относится к сюжету, характерам персонажей, визуальному ряду. Ритм у фильма медленный и плавный, притом что медлительность эта исполнена увлекающей за собой сдержанной энергии - и сама подобна дыханию песка пустыни, основного места действия картины. Ясность и прозрачность эти на самом деле волнующе многослойны. Зрителю открывается на первый взгляд стилистически единообразное, исполненное постоянства и вневременности зрелище, внушающее успокоительное ощущение надёжности, защищённости. Но это лишь поверхность, а под нею сложный и переменчивый - не так уж броско, а подобно песку, из которого состоит пустыня - мир. (Иллюстрация 1.)

Множество кадров фильма ассоциируется с живописью раннего авангарда - первых двух десятилетий двадцатого века, в первую очередь с неопримитивистскими работами художников «Бубнового валета». Особенно заметно сходство Сухова с «Отдыхающим солдатом» Михаила Ларионова (1911 год). (Иллюстрации 2-3.) Общие планы напоминают лаконичные среднеазиатские и африканские пейзажи и жанровые полотна Мартироса Сарьяна. Силуэты жён гарема в групповых сценах встречались нам у Павла Кузнецова (иллюстрации 4-5.), фигура Верещагина - у Петра Кончаловского (иллюстрации 6-7.), а его дом - у Георгия Якулова. Графическое решение подачи титров в начале фильма однозначно отсылают к русскому конструктивизму и супрематистской системе Эль Лисицкого и Малевича. Резко выделяются в общем течении картины те сцены, где Сухову в грёзах является возлюбленная жена его Екатерина Матвеевна. В них узнаваемо настроение «Северной идиллии» Константина Коровина (1886) или портретов купчих Бориса Кустодиева. (Иллюстрации 8-9.) Эти живописные реминисценции работают на стилизованный и лирикоиронический микромир воображаемых сцен - ведь настроение названных коровинских и кустодиевских полотен именно таково. 
В фильме сила неопримитива вовсе не в ниспровержении табу и эпатаже буржуа, определявших их суть во времена зарождения ${ }^{10}-$ здесь они привносят некую вневременную гармонию и веселье, что можно истолковать по меньшей мере двояко. С одной стороны, как оммаж «Бубновому валету», признание его прочности во времени: пусть социально значимое время для него и истекло, зато возможной оказалась его реутилизация в искусстве настоящего в качестве конкретной основы в визуальном мире нового кино. С другой - как знак того, что дремлющий в неопримитиве заряд бунтарства можно и нужно упрятать, чтобы сберечь для потомства, ибо в нём залог автономности искусства. У цитации конструктивизма тоже по меньшей мере две функции с позиции всего фильма в целом. Можно понимать её и как отсылку ко времени, в котором разыгрывается действие: началу двадцатых годов, когда он был определяющим направлением. Но можно и как весточку оттуда - из времени, когда в конструктивизме формулировалась универсальная, независимая от времён и народов потребность в гармонии и порядке заодно с оптимистической убеждённостью, что человек способен преобразовывать, конструировать собственное настоящее и будущее. Поскольку же очевидная отсылка к конструктивизму происходит в самых первых кадрах фильма, где в буквальном смысле слова линиями (анимацией) подчёркивается и выделяется прибытие Сухова на место действия, то Сухов-персонаж может быть понят и как носитель этого конструктивистского, преобразующего настоящее и будущее, потенциала. А так как Сухов до конца остаётся одиночкой, а в конце фильма исчезает за горизонтом, то вместе с ним исчезает из кадра и обещание конструктивизма, что нетрудно истолковать как рефлексию на политику искусства шестидесятых годов.

Самое замечательное в этой сложности визуального мира фильма, что она необычайно действенна: работает, даже если мы не слишком подкованы в изобразительном искусстве. Но для искушенного зрителя радость и волнение неожиданных открытий многократно усиливают впечатление от фильма.

Многослойность под лаконичной поверхностью явственно ощутима и в структуре фильма. Выстраивая историю и характеры, Мотыль следует хорошо известным, отработанным схемам вестерна и народного эпоса, а фильм всё равно не схематичен и не банален. Отчасти именно благодаря тому, что два, по видимости противоположных культурных круга, топосы американского и русского фольклора ${ }^{11}$ играют друг на друга. Отчего оба слоя оказываются в ином, новом освещении, и нас попросту

\footnotetext{
10 Что и по сей день почти все искусствоведческие и общественно-политические трактовки выделяют в качестве их по сути единственно значимого аспекта.

${ }^{11}$ По-моему вестерн правомерно трактовать и как фольклорный слой североамериканской культуры.
} 
выбивает из обкатанной колеи восприятия: ведь до этого общим местом была невообразимость переходов между мирами востока и запада! Получается, что сочетание двух схематизмов гасит схематизм как таковой, действие захватывает, волнует от начала до конца, тогда как сам по себе традиционный вестерн так же предсказуем в каждом своём повороте, как и народная сказка.

«Белое солнце пустыни» соприкасается и с лучшими образцами русской прозы первой половины 20 века. И фильм целиком, и особенно главный герой Сухов чем-то сродни миру вещей Андрея Платонова, точнее, некоторым платоновским персонажам: им неизменно присуща вера в человеческую доброту, и кроткая, незатейливая, но убеждённая тяга к добру. При этом всё происходящее с ними овеяно безысходностью, и почти все они одиноки. Вслушавшись в слова Мотыля, можно догадываться, что и сам он, наверно, ощущал себя в схожем силовом поле, когда ставил свои фильмы или когда добивался их выхода в свет. Внутреннее родство Мотыля с платоновскими героями, особенно с Пуховым из «Сокровенного человека» в связи с «Белым солнцем» подметил и Андрей Кончаловский ${ }^{12}$. Конечно, есть явное сходство в сюжетах и месте действия повести Платонова и фильма Мотыля (гражданская война, красные и белые, дорога домой, Каспийское побережье). Но как мне кажется, Сухов куда больше сродни Саше Дванову из «Чевенгура» - тут пребывание в пути, верность убеждениям, готовность прийти на помощь, решительность, наивность, никогда-не-прибытие, дальние привязанности, одиночество. Есть у Сухова реплики, едва ли не дословно вторящие Дванову ${ }^{13}$.

Михаил Филиппов, исполнитель главной мужской роли в последнем фильме Мотыля, вышедшем на экраны в 2010 году, сравнивает самого режиссера с платоновскими литературными персонажами. Он говорит, что кино для Мотыля - такой же цельный и не зависящий ни от чего дивный мир, как мир поездов для машиниста Мальцева из «В прекрасном и яростном мире» ${ }^{14}$. Стоит отметить два стилистических момента. С вещами Платонова «Белое солнце пустыни» роднит лаконичный, ухватывающий суть вещей язык, причём в фильме это относится не только к диалогам: декорации, реквизиты, костюмы - всё точно так же сведено к минимуму.

\footnotetext{
12 Кончаловского цитирует Денис Корсаков (КОРСАКОВ 2020: URL).

13 Две реплики Сухова необычайно близки характеру Саши Дванова, и обе об отношении к смерти. Одна, это когда Сухов рассуждает о разнице - всего ничего - между жизнью и смертью: «Мертвому, конечно, спокойней, да уж больно скучно. А что у тебя с этим, с Джавдетом?». В другом эпизоде бандит спрашивает у Сухова: «-Тебя как, сразу прикончить или желаешь помучиться? -Лучше, конечно, помучиться», отвечает Сухов. Дванов в Чевенгуре попадает в схожие переделки и вступает в схожие диалоги.

${ }^{14}$ Высказывание Михаила Филиппова (ТАЙНЫ КИНО 2019: URL).
} 
Второй момент касается атмосферы: и у того, и у другого автора трагедия и героический поступок напрочь лишены пафоса. За методом угадывается убеждённость, что всякий человеческий поступок одновременно соприкасается и с настоящим, и с вечностью. И если держишь в уме эту двойственность, то пафос как выражение преходящей и изменчивой оценки теряет смысл, неуместен, не стоит того. Эта особенность выдает своеобразную и схожую у обоих авторов жизненную философию: тут их отношение к универсальному времени и сменяющимся историческим системам и позиция, касающаяся внутренней автономности индивидуума. В своём некрологе киновед Михаил Трофименков пишет о Мотыле: «Его шедевры... определяли интонацию эпохи не только и не столько в кино, сколько в самой жизни Советского Союза.» (ТРОФИМЕНКОВ 2010: URL).

\section{Литература}

КОРСАКОВ Д. (2020) Чтобы Владимир Мотыль мог снять «Белое солнце...», солдатам пришлось пропалывать пустыню // Комсомольская правда 20.03.2020. https://www.kp.ru/daily/27110.5/4186960/ (Дата обращения: 17.08.2020.)

МОТЫЛЬ В. (1998) В кино нужна госполитика // Коммерсантъ №104 от 11.06.1998. 9. https://www.kommersant.ru/doc/200046 (Дата обращения: 17.08.2020.)

РАЗДАКОВ Ф. (2008) Гибель советского кино. Интриги и споры. 1918-1972. Эксмо, 2008.

СТАРОДУБЕЦ А. (2005) Анатолий Кузнецов: «Белое солнце» меня согрело и обожгло // Труд №246 от 30.12.2005. https://www.trud.ru/article/30-12 2005/98903 anatolij kuznetsov beloe solntse menja sogrelo i o.html (Дата обращения: 17.08.2020.)

ТРОФИМЕНКОВ М. (2010) Режиссер эпохи. Умер Владимир Мотыль // Коммерсантъ №31 от 24.02.2010. 15. https://www.kommersant.ru/doc/1327033 (Дата обращения: 17.08.2020.)

ШУБИН А.В. (2008) Золотая осень, или период застоя. СССР в 1975-1985 гг. Серия Тайны советской эпохи. Вече, 2008.

\section{Другие источники}

БРАВЕРМАН С. (2016) «Белое солнце пустыни» - от заката до восхода. Документальный фильм, 2016. https://www.1tv.ru/doc/za-kadrom/beloe-solncepustyni-ot-zakata-do-voshoda-dokumentalnyy-film (Дата обращения: 17.08.2020.)

КАК СОЗДАВАЛСЯ (2011) Как создавался фильм «Белое солнце пустыни». Режиссер: нет данных, Киновидеообъединение «Крупный план», 2011. https://www.youtube.com/watch?v=DNaq53rtge4\&t=520s $\quad$ (Дата обращения: 17.08.2020.)

НАСОНОВ А. (2012) Белая звезда снегопада. Документальный фильм, 2012. https://www.youtube.com/watch?v=D-JFG-mccBk (Дата обращения: 17.08.2020.) 
ПОЧТИ МОНОЛОГ (б.г.) Владимир Мотыль. Почти монолог. Отрывок из телерепортажа. Без данных о создателях. https://www.youtube.com/watch? v=IeHvX5Lo3PU (Дата обращения: 17.08.2020.)

ТАЙНЫ КИНО (2019) Владимир Мотыль - Москва24. Телепередача от 16.04.2019., Телеканал Культура. https://www.m24.ru/shows2/77/202968 (Дата обращения: 17.08.2020.)

ТРОИЦКИЙ Н. (2007) Кино - дело тонкое. Владимир Мотыль. Документальный фильм, 2007. https://tvkultura.ru/brand/show/brand id/28176/ (Дата обращения: 17.08.2020.)

ЮРЬЕНЕН С. (2011) «Белое солнце пустыни». Беседа с создателями // Радио Свобода. 24.05.2011. https://www.svoboda.org/a/24204633.html (Дата обращения: 17.08.2020.)

\section{Иллюстрации}

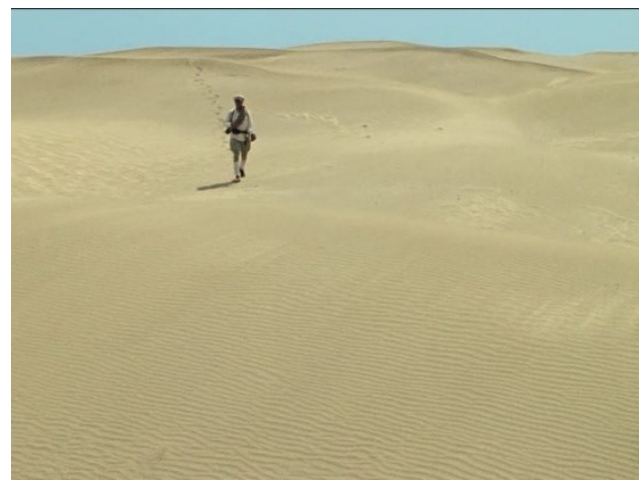

1. Кадр из фильма. Товарищ Сухов появляется в истории.

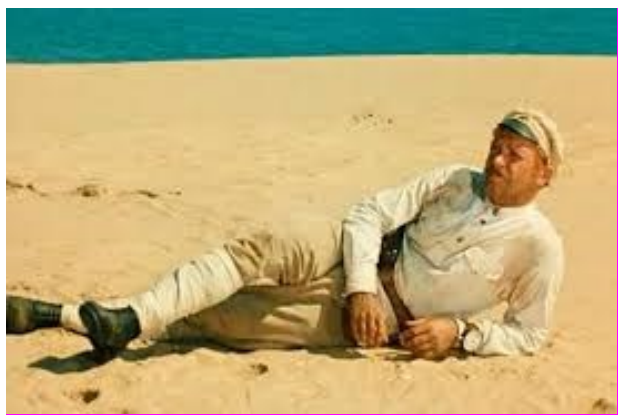

2. Кадр из фильма. Товарищ Сухов.

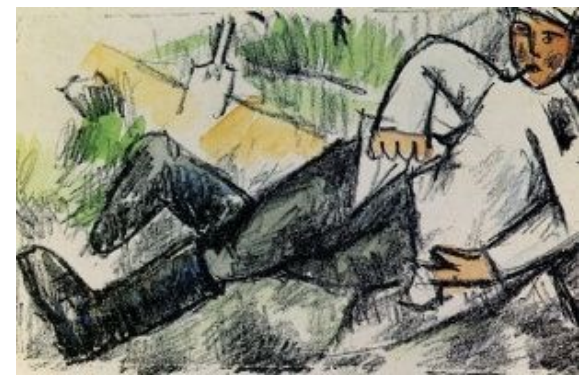

3. Михаил Ларионов: Отдыхающий солдат (1912) Источник: https://art. biblioclub.ru/picture 24278 otdyihayu schiy soldat iz serii litografirovannyi $\underline{\text { h otkryityih pisem izdannyih a kruc }}$ henyih/ 


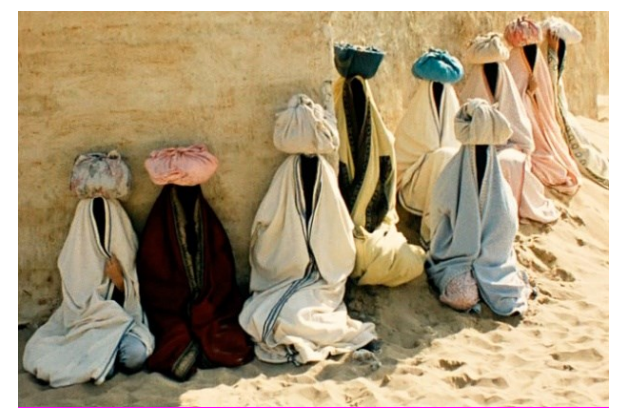

4. Кадр из фильма. Гарем ждет своей судьбы.

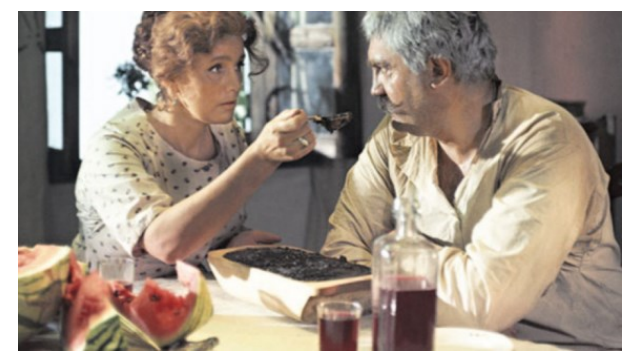

6. Кадр из фильма. Верещагин с женой.

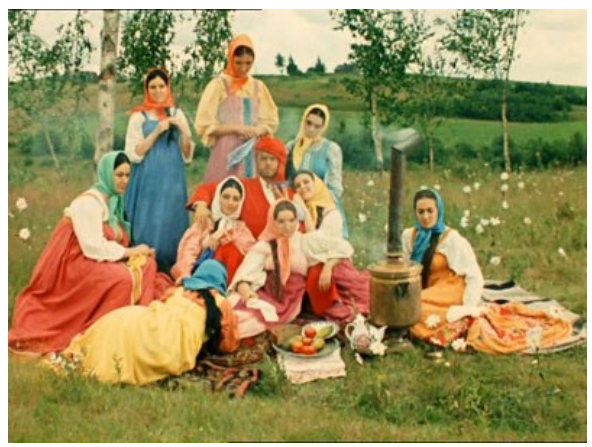

8. Кадр из фильма. Гарем во сне Сухова.

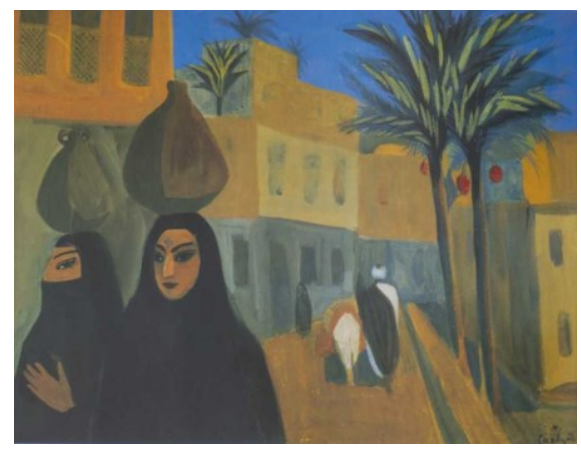

5. Мартирос Сарян: Женщины (1914) Источник: https://artinvestment.ru/ news/exhibitions/20171116 martiros s aryan exhibition in tretyakov gallery. $\underline{\mathrm{html}}$

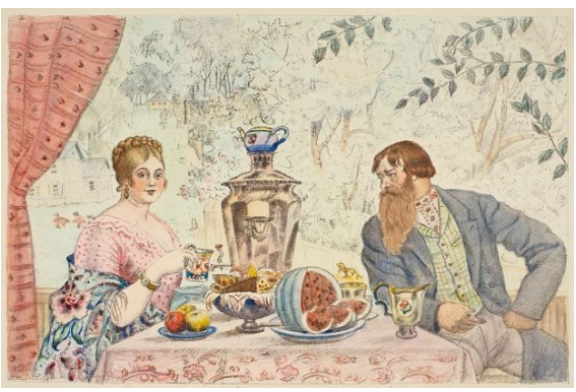

7. Борис Кустодиев: Купец и купчиха (1921) Источник: https://www.litfund. ru/auction/96/109/

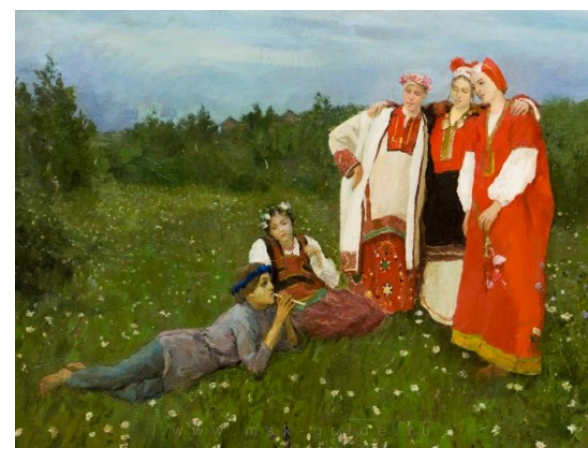

9. Константин Коровин: Северная идиллия (1886) Источник: https://www.wikiart.org/ru/konstantinkorovin/severnaya-idilliya-1886-0 
References to Fine Arts in Vladimir Motil's Feature Film "White Sun of the Desert". The Soviet feature film "White Sun of the Desert" (1970) by Vladimir Motil is considered a landmark in many ways. The circumstances of filming, screening, release, audience reaction, and the genre and formal language of the film itself all are significant. The article focuses on the filming process in the experimental studio ETO, the specificities of the genre called eastern and some features of the movie's formal language, namely, the reminiscences of paintings by artists such as Korovin, Kuznetsov, Kustodiev, Larionov, Malevich, Sarian, Jakulov from the beginning of the 20th century.

Keywords: Vladimir Motil, The White Sun of the Desert, eastern, paintings of the beginning of the 20th century 